\title{
IX. On the production of spectra by the oxyhydrogen flame
}

\section{Tasker H. Marvin}

To cite this article: Tasker H. Marvin (1876) IX. On the production of spectra by the oxyhydrogen flame, Philosophical Magazine Series 5, 1:1, 67-68, DOI: 10.1080/14786447608639003

To link to this article: http://dx.doi.org/10.1080/14786447608639003

曲 Published online: 13 May 2009.

Submit your article to this journal $[\pi$

Џ Article views: 2

Q View related articles $₫$ 
configuration a function of $h$ and $v$, the function $\frac{d Q}{\mathrm{~T}}$ is still an exact differential.

Let $\delta_{2} \chi$ or $\frac{d_{2} \chi}{d h} \delta h+\frac{d_{2} \chi}{d v} \delta v$ be the new alteration in $\chi$, which is not the equivalent of work done, and let $\delta_{2} \bar{\chi}$ be the mean value of $\delta_{z} \chi$.

Then, as the alteration is supposed to take place without expense to $\delta Q_{1}, \delta_{2} \bar{\chi}$ must be subtracted from the whole change of the ergal in the expression for $\delta Q$. The equation (A) then becomes

$$
\frac{\delta \mathrm{Q}}{\mathrm{T}}=-\lambda \frac{\delta h}{h}+\frac{2}{3} h \delta \bar{\chi}-\frac{2}{3} h \delta_{2} \bar{\chi}+\frac{2}{3} h \mathrm{P} \delta r .
$$

Under the circumstances (B) becomes

$$
\begin{aligned}
\delta u & =-\bar{\chi} \delta h+\lambda \frac{\delta v}{v}-h \frac{\overline{d \bar{\chi}}}{d v} \delta v-h \frac{\overline{d_{2} \chi}}{d h} \delta h-h \frac{\overline{d_{2} \chi}}{d v} \delta v \\
& =-\bar{\chi} \delta h+\lambda \frac{\delta v}{v}-h \frac{\overline{d \chi}}{d v} \delta v-h \delta_{2} \bar{\chi}
\end{aligned}
$$

and by substitution we obtain, as before,

$$
\frac{\delta \mathrm{Q}}{\mathrm{T}}=\delta\left\{-\lambda \log h+\frac{2}{3} h \bar{\chi}+\frac{2}{3} u\right\}=\delta \phi .
$$

IX. On the Production of Spectra by the Oxyhydrogen Flame. By Tasker H. Marvin, Brooklyn, N.Y."

$\mathrm{QIX}$ or seven months since, in using the lime-light for spec$\$$ troscopic work, I had the good fortune to discover a method by which bright-line spectra, without an accompanying continuous spectrum, could be produced at will by means of the oxyhydrogen flame.

I had been engaged in examining the spectrum of calcium superimposed upon the continuous spectrum, which is easily seen by bringing the collimator of a compound spectroscope to bear laterally upon the incandescent point of the line. I found that I could bring out all the bands of calcium and the sodium line doubled sharply and brightly, notwithstanding the brightness of the continuous spectrum. When, however, the proportions of hydrogen and oxygen were so adjusted that there was no excess of the latter, the bright lines of calcium and sodium disappeared and the continuous spectrum alone remained. The chemical reaction then seemed evident; the

* Communicated by the Authot. 
excess of hydrogen at the high temperature of the flame seemed to reduce the oxide of calcium, and an atmosphere of vapour of metallic calcium partially enveloped the cylinder, and hence the double spectrum.

Following the suggestion, I soon found a simple way to eliminate entirely the continuous spectrum, leaving the other remarkably bright, sharp, and persistent. I accomplished this by taking the light from a point above or quite outside of the incandescent point of lime. After various experiments, the method adopted for producing these results most satisfactorily was to prepare artificial cylinders perforated centrally, the opening being $\frac{1}{4}$ inch in diameter ; this was slipped on the jet, which was a double one, the two jets of gas playing upon opposite sides of the inner surface of the hollow cylinder. This threw a flame directly upwards, from which the spectrum was obtained.

The incandescent points being within the cylinder, no continuous spectrum was possible; and the results produced by this device were in the highest degree satisfactory.

It was evident, if lime could thus be reduced and the metal volatilized, that other oxides could be similarly treated; I therefore had hollow cylinders of strontia prepared, from which I obtained the strontia spectrum with far greater brightness and persistency than is possible by ordinary means. Indeed, so far as my experiments have gone, I see no reason why this method is not applicable to most of the metallic oxides. In experimenting, however, with an easily fusible oxide, like that of copper, I have found it necessary to combine it with some very refractory substance, like alumina, in order to prevent fusion.

In applying this method to the projection of spectra, the results were very satisfactory, and they warrant the expectation that the projection of most spectra may be effected in this way. My experiments in this direction have been limited for want of time.

An attempt to photograph the lines projected to a distance of 2 or 3 feet was sufficiently successful to satisfy me of the practicability of the operation.

I should say that having called the attention of my friend Professor A. K. Faton to these facts, he has willingly lent his aid in the prosecution of these experiments, particularly in the line of projection.

Hoboken, New Jersey, Dec. 16, 1875. 